\title{
Luis Roberto Gerola (18/5/1960 - 11/12/2011)
}

\author{
Luis Roberto Gerola (5/18/1960 - 12/11/2011)
}

\author{
Luiz Eduardo Villaça Leão ${ }^{1}$
}

No início de 1981, fui chamado pelo Prof. José Carlos Prates ao Laboratório de Anatomia da Escola Paulista de Medicina (EPM). Lá chegando, os Profs. Prates e Nader Wafae queriam me apresentar um acadêmico secundanista do curso médico que estudava anatomia do coração. Assim, foi-me apresentado o acadêmico Luis Roberto Gerola, com o pedido que o introduzisse em aspectos cirúrgicos da anatomia do coração. Nesse dia, iniciou-se uma amizade e convívio com uma pessoa de inteligência superior, dedicação invulgar, raciocínio brilhante e enorme criatividade. A partir de então, tive o privilégio de conviver com um indivíduo brilhante ao longo de toda a sua vida acadêmica, médica e cirúrgica. Infelizmente, essa jornada foi cruelmente interrompida no apogeu de sua produção científica, intelectual e profissional, aos 51 anos de idade.

Por outro lado, eu achava que conhecia muito bem o Gerola, porém nos últimos três anos de convívio, tive a chance de conhecer outra faceta do Luis Roberto - a de lutador incansável pela sua vida - lutou tanto, resistiu a tantas intercorrências, que várias vezes parecia "ressuscitar" - homem que frente ao câncer que corroía seu pâncreas, vias biliares, artéria hepática, artéria mesentérica superior, duodeno - lutou bravamente para sobreviver e nunca rendeu-se à doença. Nessa luta injusta, venceu inúmeras batalhas - algumas das quais muitas vezes os mais próximos consideravam perdidas. Logo, estava novamente trabalhando. Poucos dias depois, estava ele de volta ao consultório, ao centro cirúrgico. Venceu diversas dessas batalhas, mas acabou perdendo a guerra contra inimigo tão traiçoeiro, injusto e cruel. Após alguns curtos períodos de internação, faleceu - como queria - em sua casa, junto a sua família, em 11 de dezembro de 2011.

O Dr. Luis Roberto Gerola nasceu em Leme, SP, em 18 de maio de 1960. Filho de Orlando Gerola e Leonilde Pecora Gerola, irmãos Orlando Gerola Junior e Luis Fernando.

O Gerola mudou-se para Limeira aos 14 anos, sozinho, morando em quarto alugado em casa de família, para cursar o Colégio Técnico em Limeira da UNICAMP, e assim concluiu o Colegial e formou-se Técnico de Enfermagem.
Nessa condição, conduziu-se ao estudo das ciências biológicas e iniciou seu aprendizado e gosto pela cirurgia ao ter oportunidade de instrumentar operações na Santa Casa de Limeira nas horas vagas. Dizia ele que aí nasceu seu interesse invulgar pela Medicina, em geral, e pela Cirurgia, em particular. Com dificuldades financeiras e à custa do seu próprio trabalho, fez cursinho pré-vestibular, morando um ano (1978) em Piracicaba, SP, e outro (1979) em Ribeirão Preto, SP. Foi aprovado no vestibular FUVEST no final de 1979, na EPM, onde realizou o curso médico, de 1980 a 1985.

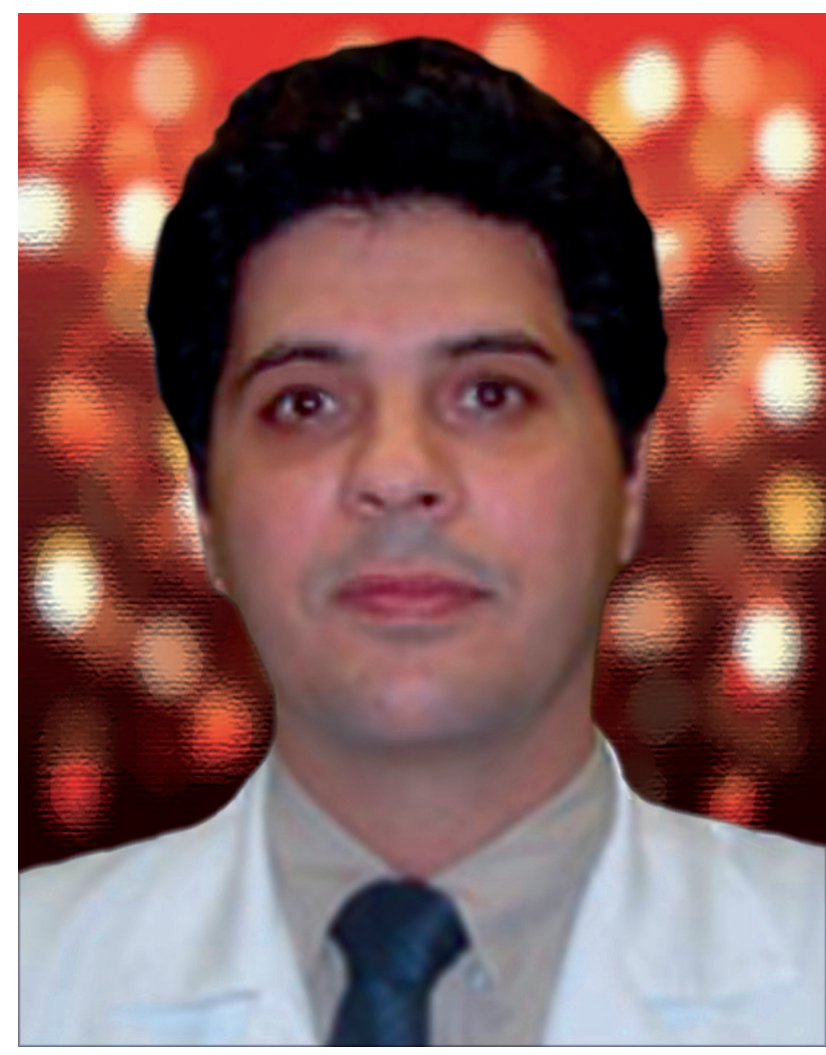

Fig. 1 - Gerola: médico brilhante e lutador incansável pela vida 
A vida do Gerola, enquanto ainda acadêmico, é impecável, tendo sido monitor oficial ou aluno de Iniciação Científica durante todo o curso, do $2^{\circ}$ ao $6^{\circ}$ ano médico. Alternou sua monitoria “oficial" (MEC) e Iniciação Científica (FAPESP) entre a Anatomia e a Cirurgia Torácica. Sempre teve um vínculo "oficial" e um "voluntário", mas nunca delas se afastou. Paralelamente a isso, para custear sua moradia e estudos, assumiu diversos cargos no Laboratório Central do Hospital São Paulo, desde plantonista até supervisor. Ainda acadêmico, escreveu vários trabalhos, como autor ou coautor, auxiliou teses e até teve a ousadia de publicar trabalho original, com considerações próprias e originais sobre anatomia e embriologia da Banda Anômala do Ventrículo Direito. Que ousadia!

Apesar das dificuldades acima assinaladas, o Gerola destacou-se demais - ainda acadêmico - na Anatomia, no Laboratório Central e na Cirurgia Torácica - e chamou atenção de todos pela invulgar dedicação, inteligência e criatividade. Ficava evidente seu amor pela Cirurgia Torácica (hoje chamaríamos Cardiotorácica) e isso o fez procurar nosso grande mestre Prof. Dr. Costabile Gallucci, grande catalisador de talentos - não apenas na ciência, mas profundo conhecedor dos homens, das suas almas, suas vocações e habilidade para colocar cada um no caminho adequado. O Prof. Gallucci acedeu imediatamente aos pedidos do Gerola e deu-lhe inúmeras oportunidades, destacando-se a chance de conviver com pessoas do quilate de Antonio C. Carvalho (seu conterrâneo) e Enio Buffolo, entre outros. Tive a honra, também, como havia ocorrido antes na Anatomia - de ser indicado pelo Prof. Gallucci como orientador do acadêmico e depois monitor Gerola e ser seu "Chefe de Plantão" na então Recuperação Pós-Operatória.

Tal situação provavelmente é a razão de ter sido convidado pelo Prof. Dr. Domingo Braile para escrever este memorial, que, mais que uma homenagem póstuma ao Luis Roberto Gerola, é sim uma homenagem a todos os colegas, amigos e admiradores que conquistou, seja na EPM, na Faculdade de Medicina da Universidade de São Paulo (FMUSP), no Instituto do Coração do Hospital das Clínicas da FMUSP (InCor) e nos demais hospitais onde trabalhou como cirurgião ou intensivista - todos que tiveram o privilégio de conviver com o Gerola. Assim, aceitei essa árdua, dolorosa e triste tarefa em homenagem ao Gerola e em nome de todos que com ele conviveram, ensinaram, aprenderam ou admiraram. Eu que aqui escrevo, talvez como admirador de música (grande frustração) penso no Gerola como um Debussy (um clássico que nunca cumpriu as regras) ou no jazz, como um Bill Evans ou um David Brubeck (sempre dissonante). Brilhantismo, sempre - foi o que nunca faltou na vida de Gerola.

Formado na EPM, decidiu-se pela residência em Cirurgia Geral e depois Cirurgia Cardíaca na FMUSP e InCor. Teve a felicidade de ter como colegas e preceptores Luiz Felipe P. Moreira e Paulo Manuel Pêgo-Fernandes. Durante esse período, o Luís Roberto teve particular afinidade e admiração pelo Prof. Dr. Sergio Almeida de Oliveira e pelo Prof. Dr. Luiz Boro Puig.

Terminada a residência cirúrgica, "sobreviveu" trabalhando nas clínicas de pós-operatório de ambos os professores e manteve também atividade cirúrgica. Diferença fundamental a mencionar: ele não apenas sobreviveu financeiramente, mas ao mesmo tempo produziu trabalhos de peso com ambos os professores - que geraram publicações de repercussão internacional - com o Dr. Sergio Almeida e Dr. Puig. Nessa ocasião, vir trabalhar com o Dr. José Ernesto Succi e comigo, na nossa bem mais modesta clínica, foi um privilégio e sempre a certeza de um colega leal, honesto, sincero, competente, dedicado, inquieto e, principalmente, criativo. Cirurgião excepcional, que aliava habilidade, inteligência e brilhantismo na mais difícil tarefa do cirurgião - a tomada de decisões.

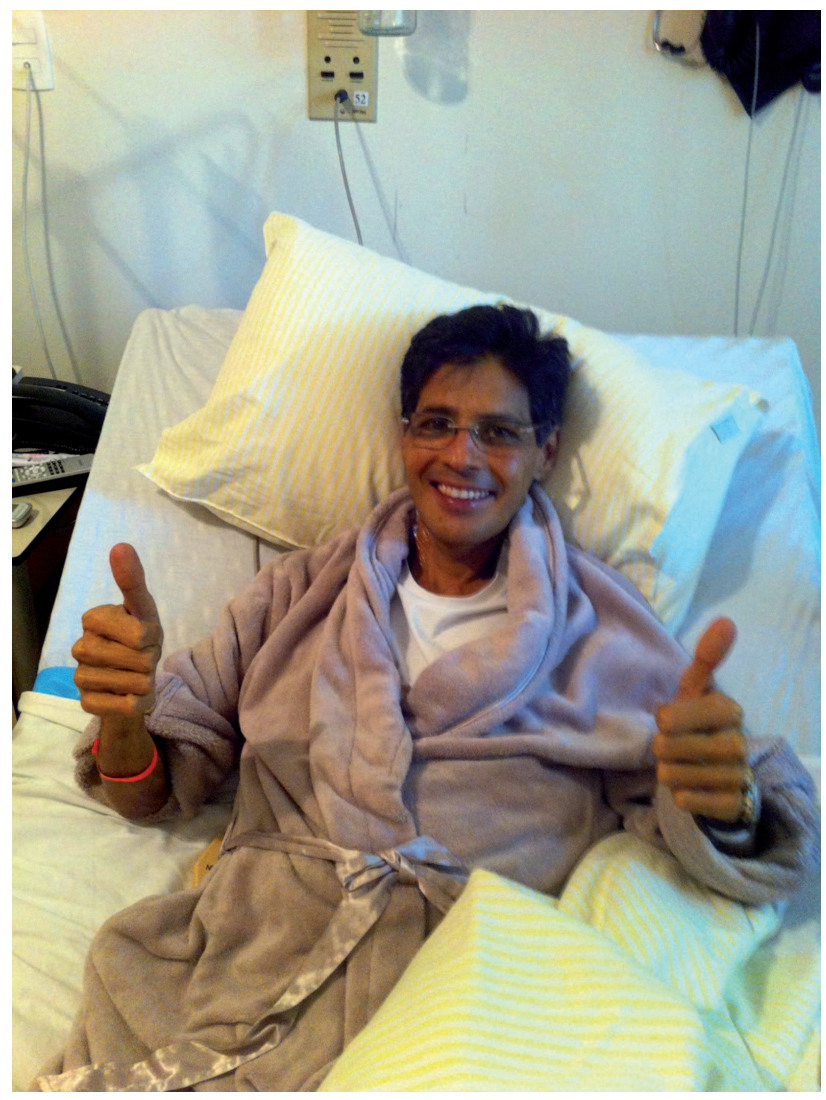

Fig. 2 - Durante cerca de 3 anos, o Dr. Gerola lutou bravamente contra o câncer, sempre mostrando otimismo contagiante

As condições de trabalho e financeiras levaram o Gerola a buscar e ter "serviços" próprios (ou com associados) em Taubaté (SP) (1993-1995) e em Cuiabá (1995-1996). Após 
este período, sofreu enorme abalo pela morte súbita de seu pai, ao final de 1996. Tal ponto foi decisivo nas decisões e rumos da vida do Gerola.

Abalado pela morte súbita de seu pai, retorna à EPM e encontra, após 11 anos de ausência, o suporte do Prof. Enio Buffolo. O mestrado já estava completo na Anatomia. A carreira universitária, doutorado (Cirurgia Cardiovascular), e pós-doutorado (FAPESP), eram a sequência natural esperada e, após concurso público, foi aprovado e entrou para o corpo docente permanente da EPM-UNIFESP, em 2002.

Já como docente na Cirurgia Cardiovascular foi presidente da Liga Acadêmica, Preceptor dos Residentes e responsável pelas cirurgias cardíacas em dialíticos crônicos ou transplantados no Hospital do Rim.

Importante notar que durante todo esse período, o Luis Roberto Gerola nunca parou de produzir colaborações importantes. Referem-se principalmente a enxertos arteriais, válvulas humanas, operação de Ross, homoenxertos aórticos e técnicas engenhosas para o reparo de comunicação interventriculares e aneurismas pós-infarto. Permito-me não discorrer sobre tais itens, por estarem amplamente disponíveis na literatura especializada e em seu currículo Lattes.

Muitas de suas atividades, contudo, não aparecem na frieza do Lattes. Até os últimos meses de sua vida trabalhava intensamente em parceria com a Prof ${ }^{\text {a. }}$ Helena Bonciani Nader - estudando aspectos de biologia molecular no endotélio de artérias radial, torácica interna - procurando explicações para o comportamento diferente desses vasos quando utilizados em posição aortocoronária. Esse trabalho ele pretendia que tornasse sua tese de Livre Docência, algo com que sonhou até seus últimos dias.

Ao longo de tantos anos de convívio, deixou em todos nós a imagem de "menino" - sempre com um sorriso nos lábios. Suas vitórias e conquistas, suas decepções eram sempre relatadas com sorriso "maroto", às vezes irônico, mas sempre conformado e otimista. Nunca vimos o Gerola com expressão fechada, magoada.

Nos últimos anos, o Gerola deu espaço para suas "origens" cirúrgicas: voltou a trabalhar parte do tempo com o Dr. José Ernesto Succi, comigo e a nossa equipe, agora enriquecida pelo Dr. Guilherme Succi; quis o destino que quando essa sinergia (Gerola - Guilherme) expressava-se em seu máximo, no auge de sua criatividade e entusiasmo, o Gerola aparece subitamente icteríco sem causa aparente e a investigação acaba revelar-se um carcinoma da cabeça do pâncreas.

Durante cerca de 3 anos, o Gerola lutou bravamente. Continuou atendendo em consultório, escrevendo "papers" e mesmo operando. Ao longo da longa luta contra o câncer, inúmeras vezes zombava de sua própria situação, suas dores, semioclusões, diarreia, emagrecimento. Nos últimos meses, por diversas vezes despediu-se de mim, no consultório, dizendo - "vou descendo antes para dar um pulo ali na feira-livre, para comer pastel e tomar garapa, acho que assim eu engordo um pouco".

Conversamos bastante dois ou três dias antes de sua morte. Mas ele não queria falar de doença - queria conversar sobre um concurso que eu tinha examinado dias antes, qual o ponto sorteado, como foi a aula, etc. Senti que estava cansado, ofegante. Encerrei a conversa alegando outro motivo e disse que continuaríamos a conversa na segunda feira. Não deu tempo, ele morreu na tarde de domingo, 11 de dezembro. Recebi a notícia de sua morte e arrumei-me para ir ao velório. Já pronto para sair, desisti no elevador. Não tive coragem de vê-lo morto; egoísta, talvez, preferi guardar comigo a imagem sempre sorridente do meu amigo Luis. Voltei para casa, abri uma garrafa de vinho e fui ouvir música e escrever. A música que tocava era algo que marcou muito minha juventude e sempre me faz lembrar do Gerola e daqueles cuja vida é ceifada tão precocemente. A música chama-se Abraham, Martin \& John (1968), letra e música de Richard Holler.

Has anybody here seen my old friend....?

Can you tell me where he's gone?

He freed a lot of people, but it seems the good they die young.

You know, I just looked around and he's gone.

1. Professor Titular da Disciplina de Cirurgia Torácica. Departamento de Cirurgia da Escola Paulista de Medicina da UNIFESP, São Paulo, SP, Brasil.

E-mail: drluizleao@gmail.com 